\title{
Sea surface temperature anomalies, seasonal cycle and trend regimes in the Eastern Pacific coast
}

\author{
A. Ramos-Rodríguez ${ }^{1,3}$, D. B. Lluch-Cota ${ }^{1}$, S. E. Lluch-Cota ${ }^{1}$, and A. Trasviña-Castro ${ }^{2}$ \\ ${ }^{1}$ Programa de Ecología Pesquera, Centro de Investigaciones Biológicas del Noroeste, S.C., La Paz, Mexico \\ ${ }^{2}$ Departamento de Oceanografía Física-Unidad La Paz, Centro de Investigación Científica y Educación Superior de Ensenada, \\ Ensenada, Mexico \\ ${ }^{3}$ Universidad Tecnológica del Mar de Tamaulipas Bicentenario, La Pesca, Tamaulipas, Mexico
}

Correspondence to: A. Ramos-Rodríguez (jaramosr3110@utmart.edu.mx)

Received: 10 May 2011 - Published in Ocean Sci. Discuss.: 25 May 2011

Revised: 10 October 2011 - Accepted: 13 December 2011 - Published: 15 February 2012

\begin{abstract}
We used the extended reconstruction of sea surface temperature (ERSST) to analyze the variation of surface temperature and the seasonal cycle along the coast of the eastern Pacific $\left(60^{\circ} \mathrm{N}-60^{\circ} \mathrm{S}, 61\right.$ pixels alongshore) from 1950 to 2010 (732 months). First, we analyzed the monthly anomalies and looked for a relationship of such anomalies with total solar irradiance (TSI) and then the Regime Shift Detector (RSD) was applied to detect possible temperature regimes in the series. Afterwards, we calculated a yearly temperature range per pixel (amplitude of seasonal cycle) and through the subtraction of a latitudinal theoretical curve of temperature based on solar irradiance, the residuals of the seasonal cycle were obtained. The results showed an almost complete spatial synchrony and dominance of negative anomalies from 1950 to mid-late 1970's, with a switch to near-zero and positive anomalies that lasted up to late 1990's when a new shift to negative values was detected. Such a shift lasted until the early 2000's when positive anomalies appeared again but there was a change to negative anomalies in the late 2000's. These results were supported by the RSD. The TSI variability shows a clear relationship with that of sea surface temperature anomalies and with the regime changes. This is probably due to a difference in the amount of energy received from the sun. Comparing the "cool regime" versus the "warm regime", the second one received $0.39 \%$ more energy (approximately $3 \times 10^{8} \mathrm{~J} \mathrm{~m}^{-2}$ ) from the sun. Seasonal cycles show larger ranges at northern latitudes $\left(>40^{\circ} \mathrm{N}\right)$, northern tropical-temperate transition zone $\left(20^{\circ}-26^{\circ} \mathrm{N}\right)$ and in the tropical-equatorial band $\left(0^{\circ}-30^{\circ} \mathrm{S}\right)$. The smallest ranges occur at $0^{\circ}-16^{\circ} \mathrm{N}$ and $50^{\circ}-60^{\circ} \mathrm{S}$. The residuals (seasonal minus the theoretical curve) indicated a clear modulation due to advection by ocean currents.
\end{abstract}

\section{Introduction}

Isaacs (1974) when talking about some issues concerning fishery science used the term "regime" referring to the prevailing of particular conditions -either biological, oceanographical, climatic, etc., over others. In this sense, a "regime" is more like an "episode", in which there is hegemony of a trend in a variable of interest. In the late 1980's Lluch-Belda et al. (1989) reported that sardine and anchovy abundance alternates or cycles in eastern boundary upwelling ecosystems (EBUE's) of the world. They used the term "regime" when one species was dominating over the other, with a "regime shift" occurring when conditions changed to the opposite. The main cause for this regime shift in abundance is warm/cool conditions on the surface of the ocean, making the ecosystem more suitable for one or the other fish species (Lluch-Belda et al., 1992; Steele, 1998; Schwartzlose et al., 1999). Climate impact on individuals and populations may operate directly through physiology (metabolic and reproductive processes) or indirectly through the ecosystem, including prey, predators and competitors (Stenseth et al., 2002). This concept of regime and regime shift of species was soon expanded to climatic factors and even to entire ecosystems and its components. It was also realized that all regimes - whether they are species, ecosystems or climate, operate in different temporal scales, from inter-annual to decadal (Hare and Mantua, 2000; Meehl et al., 2003; Scheffer and Carpenter, 2003; Sandweiss et al., 2004). The oceans act as a climatic "thermostat" and the effect of climate variability on marine ecosystems can be traced through changes in sea surface temperature (SST, Stenseth et al., 2002). In this work we decided to study variability in coastal SSTs along the eastern Pacific Ocean, from $60^{\circ} \mathrm{N}$ to $60^{\circ} \mathrm{S}$ and from 1950 to 2010 . The coastal region was chosen because most of the photosynthetic processes occur in coastal environments and 
are highly influenced by physical variables such as winds and currents, all of which have an effect on SSTs.

Incoming radiation from the sun is the main energy source and is fundamental in influencing terrestrial climate. Variations in the energy from the sun reaching the Earth's surface is often assumed to be the source of climate disparities (Reid, 1991). The spatial and temporal variation in solar radiation due to solar altitude produces seasonal variation in temperatures, precipitation and many other aspects of the atmospheric environment (Moran and Morgan, 1997). Seasonality even changes on longer time scales, mainly due to alterations in Earth's orbital eccentricity and the tilt of planet's rotational axis, varying on recognized cycles of approximately 41 k.y. and 100 k.y. respectively, and known as Milankovitch cycles (Milankovitch, 1941; Bennett, 1990).

On shorter time scales the radiation from the sun changes and has different cycle lengths. Among them we can find the Sunspots or Schwabe cycles (11 yr; Dean, 2000), Hale cycles (22 yr; Dean, 2000), Gleissberg cycles (88 yr; Braun et al., 2005; Peristykh and Damon, 2003), DeVries-Suess cycles (210 yr; Wagner et al., 2001), Hallstat or Hallstadtzeit cycles ( 2400 yr; Charvátová, 2000; Vasiliev and Dergachev, 2002). Such variability in the radiation from the sun has an effect on the climate dynamics of the Earth and it is the main motor (Rind, 2002). Here we study the variability along the coast of the eastern Pacific and we compare it with the variability in solar radiation. The hypothesis is that solar cycles should be present in records of different oceanographic variables modulated by other important processes such as the ocean currents.

The work is organized as follows. The following section describes the data and methodology used for its analysis. Section 3 discusses our results and a final section is dedicated to summarize our findings and for the concluding remarks.

\section{Methodology}

\subsection{Sea surface temperature data and total solar irradiance data}

For SSTs we used the extended reconstruction of sea surface temperature data set (ERSST). This is a database with a latitudinal and longitudinal spatial resolution of $2^{\circ}$ by $2^{\circ}$ for each data point (pixels) and a time resolution of one month. For the analysis we selected pixels from the eastern Pacific coast at $60^{\circ} \mathrm{N}$ to $60^{\circ} \mathrm{S}$ and only the pixels nearest to the coastline (61 pixels in total). ERSST data was generated from NOAA's Historical Merged Land-Ocean Surface Temperature Analysis, version 3b (http://www.ncdc. noaa.gov/oa/climate/research/sst/ersstv3.php) and it includes data from January 1950 to December 2010, for a total of 732 months. The data in ERSST starts in 1854 but we decided to use only the above-mentioned period because the reported confidence interval for uncertainty for the quasi- global average for 1950 onwards is of $0.1{ }^{\circ} \mathrm{C}$. Improved fit procedures are also included for this period along with the omission of satellite observations due to the larger residual bias of such observations (Smith and Reynolds, 2003, 2004; Smith et al., 2008). The total solar irradiance data (TSI) was obtained from the SOLARIS working group web page hosted by the Physics of the Middle Atmosphere Group of the Freie Universität of Berlin (http://www.geo.fu-berlin.de/ en/met/ag/strat/forschung/SOLARIS/Input_data/). Here they include data for the period 1880-2004. Such data is calculated with the use of observational data and proxies. It includes corrections for wavelength-dependent degradation common to measurements of TSI. A more detailed description of these estimates can be found in Lean et al. (1997), Lean (2000) and Lean et al. (2005).

To determine the exact length and timing of every cycle the Cyclic Descent Method was used (Bloomfield, 1976). The latter method is useful to define the cycles present within a time series and fits a polynomial model that can be employed to forecast.

\subsection{Monthly anomaly analysis}

For the SST data, the monthly anomalies for each $2^{\circ}$ by $2^{\circ}$ coastal pixel were calculated by obtaining a mean of all months in the database resulting in an annual mean time series per pixel. This was then subtracted from individual monthly values in the time series.

In order to detect the presence of a SST regime shift in the different time series we used the Regime Shift Detector (RSD, Rodionov, 2004; Rodionov and Overland, 2005). The RSD is a useful tool to detect abrupt changes in a time series by t-test analysis of either the mean or variance, and it is useful also since it can detect a shift with a minimum delay and not to be biased by long intervals when the observations remain above or below the overall mean value (red noise). Here the RSD was used with a significance level of $90 \%$ $(p<0.1)$, cut-off length of 60 month and Huber's weight parameter of 1 . For the red-noise estimation, the Inverse Proportionality with 4 corrections (IP4) method was selected, using a sub-sample size of 39. Before applying the RSD a data pre-whitening was carried out (Rodionov, 2006). With the parameters above mentioned, we expect this method will detect a SST regime at least $5 \mathrm{yr}$ long.

\subsection{Seasonal amplitude cycle analysis}

Changes in the seasonal cycle are studied from yearly amplitudes obtained for each pixel and every year in the data base. To calculate the deviations from the amplitude of seasonal cycle we computed for every pixel the annual mean solar irradiance. The latter is a function of the latitude and the movement of the sun throughout the sky during a year. Therefore, we use equations based on the spherical law of cosines and equations modified from Spencer (1971) and 
Jacobs et al. (2004). First, we obtain the solar declination for a given year using,

$\delta_{t}=\epsilon \cdot \sin \left(\left(d_{t}-(21+28+31)\right) \cdot \frac{\pi}{182.5}\right) \cdot \frac{\pi}{180}$

where, $\delta_{t}$ is the solar declination, $\epsilon$ is the Earth's axial tilt $\left(23.44^{\circ}\right)$ and $d_{t}$ is time in Julian days. To obtain the solar altitude or azimuth $(\alpha)$ series for a particular latitude we used,

$$
\begin{aligned}
\alpha_{t}=\arcsin \left(\sin (\text { Lat }) \cdot \sin \left(\delta_{t}\right)+\right. & \cos (\text { Lat }) \\
& \left.\cdot \cos \left(\delta_{t}\right) \cdot \cos \left(Y_{t}\right)\right) \cdot \frac{180}{\pi}
\end{aligned}
$$

where, Lat is a given latitude in radians and $Y_{t}$ is the hour of the day. For every latitude in the study (pixel), $\alpha$ was computed, and then the solar irradiance for such latitude $\left(\operatorname{Irr}_{\text {Lat } t \mid t}\right)$ was calculated as

$\operatorname{Irr}_{\text {Lat } \mid t}=\sin \left(\alpha_{t} \cdot \frac{\pi}{180}\right) \cdot \operatorname{Irr}_{\text {net }}$

where $I r r_{\text {net }}$ is the amount of net solar irradiance received by the Earth's surface $\left(344 \mathrm{~W} \mathrm{~m}^{-2}\right)$. We assumed an albedo of 0.3 , hence the net solar irradiance used was $240.8 \mathrm{~W} \mathrm{~m}^{-2}$. The amplitude of the solar irradiance for each pixel (latitude) was obtained calculating the statistical range. This results in a theoretical latitudinal solar irradiance amplitude series (the amplitude value of solar irradiance for every pixel), which was used to compute regressions against their corresponding latitudinal mean SST seasonal amplitude series, which was calculated averaging the 61-yr SST amplitude series for each pixel (see Sect. 2.2), resulting in one mean SST amplitude value for every pixel (latitude) used in this study. The regression was carried out in two steps: (1) from equator to $60^{\circ} \mathrm{N}$ and, (2) from equator to $60^{\circ} \mathrm{S}$, resulting in a theoretical curve of latitudinal SST amplitude based on solar radiation (amplitude of the solar irradiance, red line in Fig. 1a).

\section{Results and discussion}

\subsection{Meridional coastal variability: mean seasonal SST cycle and theoretical seasonal cycle based on solar irradiance curve}

Figure 1a compares the annual mean SST range with the theoretical seasonal temperature amplitude obtained from the irradiance cycle. This is shown for all coastal stations along the eastern Pacific. The statistical temperature range (maximum - minimum) was calculated for every year in the data base. From $60^{\circ}$ to $56^{\circ} \mathrm{N}$ in the region of the Alaska Current the seasonal cycle is 0.6 to $1^{\circ} \mathrm{C}$ larger than the theoretical curve (TC). This is because this current is relatively warm and tends to increase the amplitude of the seasonal cycle. From $54^{\circ}$ to $46^{\circ} \mathrm{N}$ the mean SST range is close to the TC with differences less than $0.47^{\circ} \mathrm{C}$, most of them above the TC. This is thought to occur here because this region does not have coastal upwelling sites and the California Current is found far from the coast. From $44^{\circ}$ to $30^{\circ} \mathrm{N}$ is an area influenced by both the California Current and coastal upwelling. This is a temperate zone with a seasonal SST range of about $5-6{ }^{\circ} \mathrm{C}$, nevertheless upwelling and California Current make this area cooler and more homogeneous, thus reducing the seasonal cycle and the SST range falling below the TC $(0.45-$ $\left.1.5^{\circ} \mathrm{C}\right)$ with smaller differences in the latitudinal band $36^{\circ}-$ $34^{\circ} \mathrm{N}$. From $20^{\circ}$ to $26^{\circ} \mathrm{N}$ the SST range is above that of the $\mathrm{TC}$ with values ranging from 1 to $2^{\circ} \mathrm{C}$ and the largest differences are found at 24 to $26^{\circ} \mathrm{N}$. Here the increase in seasonal SST range is due to the influence of tropical waters in the late summer and the presence of either the California Current or coastal upwelling lowering the coastal SSTs most of the year. The latitudinal band from $18^{\circ} \mathrm{N}$ to $2^{\circ} \mathrm{N}$, which includes the eastern Pacific warm pool and north equatorial region, shows values close to the $\mathrm{TC}$ with differences no larger than $0.5^{\circ} \mathrm{C}$. As mentioned by Fiedler and Talley (2006), this warm band marks a thermal equator where the amplitude of the seasonal cycle is low. To the south, from the Equator to $28^{\circ} \mathrm{S}$ we find the Humboldt or Peru Current region and intense coastal upwelling. This region is embedded in a tropical area and it should have a smaller SST range (around $2-3{ }^{\circ} \mathrm{C}$ ) but due to the cold current and the upwelling the seasonal cycle is much greater $\left(>6^{\circ} \mathrm{C}\right)$. Consequently, the range is above the TC (values between $0.8-5.1^{\circ} \mathrm{C}$ ) with largest differences in the upwelling region between $4^{\circ}$ and $12^{\circ} \mathrm{S}\left(4\right.$ to $5.1^{\circ} \mathrm{C}$ ). From $30^{\circ} \mathrm{S}$ and to the south the mean SST range diminished progressively. The difference of TC and average annual SST range over the $61 \mathrm{yr}$ was lower at both $42^{\circ} \mathrm{S}$ and $58^{\circ} \mathrm{S}$ being $1.2^{\circ} \mathrm{C}$ and $5.15^{\circ} \mathrm{C}$ lower, respectively. This is attributed to the influence of the Circumpolar Current and its extension to the north along the American coast (see also Sect. 3.3). Table 1 summarizes results shown above.

Mean SSTs showed a latitudinal gradient (Fig. 1b) with cooler temperatures at higher latitudes (coolest at $60^{\circ} \mathrm{S}$, $4.1^{\circ} \mathrm{C}$ ), as expected, and warmer temperatures near the equator with the warmest SST north of the equatorial region, from the $6^{\circ}-18^{\circ} \mathrm{N}\left(27^{\circ}-28.5^{\circ} \mathrm{C}\right)$ including the coast of the eastern Pacific warm pool $\left(\sim 6^{\circ}-14^{\circ} \mathrm{N}\right)$.

\subsection{SST monthly mean anomalies, solar irradiance and Regime Shift Detector (RSD)}

Figure 2 shows the time series for the total solar irradiance (2a), the Hovmöller diagram (latitude vs. time) of the SST monthly anomalies (2b) and the Hovmöller diagram of the RSD applied to every SST anomalies time series (2c). Note that we used the regime mean obtained with the RSD applied to every SST monthly anomaly series to generate Fig. 2c, hence the color bar is representing the mean value for the regime detected and is in the same units as $\operatorname{SST}\left({ }^{\circ} \mathrm{C}\right)$.

Total solar irradiance (TSI) data (2a) showed 4 full solar cycles for the period studied. To determine the exact length and timing of every solar cycle the Cyclic Descent Method 


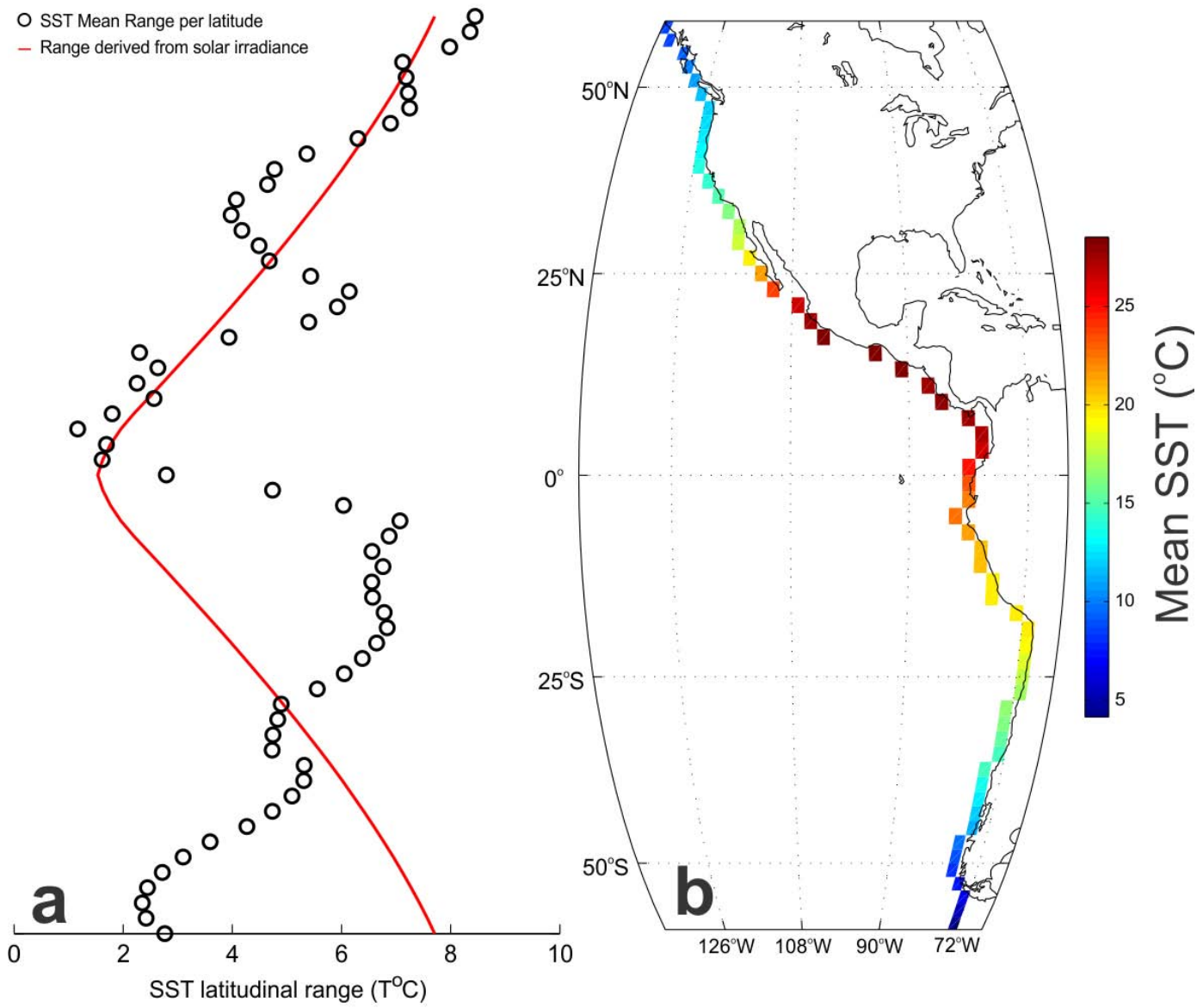

Fig. 1. (a) Mean latitudinal SST range for the selected pixels for the same period (black circles) and the theoretical SST range derived from solar irradiance (red line). (b) Coastal stations (pixels) selected for the study with their mean SST for the 61 yr in the data base.

Table 1. Observed SST range, expected SST range, range difference and likely cause of such difference for seven latitudinal bands found in the study. $\mathrm{AC}=$ Alaska Current, $\mathrm{CC}=$ California Current, EPWP $=$ eastern Pacific warm pool, HC $=$ Humboldt or Peru Current, CirC $=$ Circumpolar Current.

\begin{tabular}{lllrl}
\hline Latitudinal band & Observed & Expected & Difference & Alteration due to \\
\hline $60^{\circ}-56^{\circ} \mathrm{N}$ & 8.26 & 7.57 & 0.69 & AC \\
$46^{\circ}-54^{\circ} \mathrm{N}$ & 7.13 & 6.94 & 0.19 & CC away from coast \\
$44^{\circ}-30^{\circ} \mathrm{N}$ & 4.73 & 5.69 & -0.96 & CC and upwelling \\
$28^{\circ}-20^{\circ} \mathrm{N}$ & 5.52 & 4.22 & 1.29 & $\mathrm{CC}$, upwelling and tropical waters \\
$18^{\circ}-2^{\circ} \mathrm{N}$ & 2.22 & 2.49 & -0.27 & Tropical waters and EPWP \\
$0^{\circ}-28^{\circ} \mathrm{S}$ & 6.15 & 3.01 & 3.14 & HC and upwelling \\
$30^{\circ}-60^{\circ} \mathrm{S}$ & 3.96 & 6.43 & -2.48 & HC and CirC \\
\hline
\end{tabular}

was used (described in the methods section). This method is useful to define the cycles present within a time series and fits a polynomial model that can be employed to forecast the behaviour of a periodic component of the signal (2a, blue line, $R^{2}=0.78$ ). The position of the start/end of each solar cycle was determined using this method and in Fig. 2 it is marked by black horizontal lines.
TSI series begin with the end of a previous period (195053 ) and then the signal contains an 10.5-yr solar cycle from January 1954 to May 1964 . This solar cycle has a minimum/maximum irradiance value of $1365.5 / 1367.5$. This is followed by a longer (11.5-yr) solar cycle from June 1964 December 1975. This was also the solar cycle with the lowest 
irradiance of the whole TSI series with minimum/maximum values of 1365.3/1366.3. The next two solar cycles lasted 10.5 each. The first one goes from January 1976 to July 1986 and the second from August 1986 to December 1996. The minima and maxima for both solar cycles are almost identical, around 1365.4 and 1367.1, respectively. The remaining portion of series showed an incomplete period of increasing TSI trend.

In the following two panels of the Fig. 2 we show the SST anomalies and the regime shift detector applied to it. Negative values of SST anomalies (Fig. 2b) dominated the period of 1950 to 1978 (SST regime 1 in 2c). Zero and positive anomalies dominated from 1979 to 1999 (SST regime 2 in 2c) and mostly weak anomalies from 2000 onwards (SST regime 3 in 2c). During first SST regime negative anomalies of $2{ }^{\circ} \mathrm{C}$ were common and only during El Niño Southern Oscillation (ENSO) events (1957-1958, 1965-1966, 1968$1969,1972-1973,1976-1977)$ is that near-zero or positive anomalies could be observed. During each ENSO event the intensity of the anomaly and its zonal extent are an indication of the strength of individual occurrences. In most ENSO events, positive anomalies in the Southern Hemisphere range from the equator to about $16^{\circ} \mathrm{S}$. However, during some of the more intense ENSO events (v.g. 1957-1958) positive anomalies extend poleward to $30^{\circ} \mathrm{S}$ and to $60^{\circ} \mathrm{N}$. Mid-intensity ENSO events resulted in a weaker response in the Northern Hemisphere. During SST regime 2 (warm), from 1979 to about 1999, there was a clear dominance of near zero to positive anomalies with the only exception of the negative anomalies associated to negative ENSO (La Niña) events. The strongest ENSO events of the whole series occurred during this warm SST regime, for instance during 19821985 and 1997-2000 events. Such events have the widest zonal extent. In the 1997-1998 event, positive anomalies were recorded along the coast from $56^{\circ} \mathrm{S}$ to $60^{\circ} \mathrm{N}$. The second SST regime shift occurred around 1998-1999, after the strongest ENSO event recorded in this time series. First, a shift back towards negative anomalies occurred, lasting about 6 yr. Then a brief near-zero to warm-anomaly period occurred in 2003 only to switch again to negative anomalies around 2007-2008. The main features of this period are: a) the weak character of the anomalies throughout the coastal region and $b$ ) the lack of strong ENSO events. These brief and weak events are similar to the El Niño-Modoki class of ENSO events. Such behaviour has been described as a consequence of climate change by Ashok and Yamagata (2009).

The behaviour of the total solar irradiance curve (2a) is consistent with the regimes described by the SST anomaly curves (2b). During the cool SST regime (1950 to 1978, as seen in $2 b$ and $2 c$ two full solar cycles took place. The first solar cycle is short and reaches the highest TSI values of the two. The second solar cycle is an elongated cycle with comparatively lower TSI maximum. This shows a clear relationship with the SST anomalies. The maximum of the first solar cycle occurred during the El Niño 1957-1958 and dur- ing 1964-1975 the TSI reached a minimum and the period was dominated by negative anomalies. This TSI cycle is also the longest of the whole series, lasting $11.5 \mathrm{yr}$ in total. As pointed out by Friis-Christensen and Lassen (1991) longer sunspot cycles have a relationship with cooler temperatures on the planet due to weaker solar activity.

The area below the curve is the energy received in the period of integration. To compare the energy received during successive pairs of solar cycles we computed the area below the curves. The first integration is carried out for two consecutive cycles, from 1954 to 1975 (a total of $22.5 \mathrm{yr}$ ), and the second also for two consecutive cycles, from 1976 to 1996 (a total of $21 \mathrm{yr}$ ). The difference between the area below the TSI curves of the first and second SST regimes is of about $3 \times 10^{8} \mathrm{~J} \mathrm{~m}^{-2}$. This is equivalent to about $0.39 \%$ more energy received during the warm period compared to the cool period. This is a significant difference. Variations in total solar energetic output, as determined over time scales for which reliable climatic data are available, are small (less than about $0.1 \%$ ). Such percentage corresponds to a change of irradiance of approximately $1 \mathrm{~W} \mathrm{~m}^{-2}$ outside the atmosphere (or $0.2 \mathrm{~W} \mathrm{~m}^{-2}$ averaged over Earth's surface) between periods of maximum and minimum activity and over a full solar cycle (see for instance Haigh, 1996).

Furthermore, peaks in solar forcing increase the energy input to the upper ocean, increasing the latent heat flux (moisture) into the atmosphere, and moisture produced this way is carried by the trade winds towards the convergence zones where precipitation occurs. This intensified precipitation strengthens the Hadley and Walker circulations in the troposphere, with an associated increase in trade wind strength capable of increasing the strength of equatorial ocean upwelling and of lowering equatorial SSTs (Meehl et al., 2009). A consequence of this lowering of SSTs and increased upwelling is a positive feedback due to enhanced subsidence producing fewer clouds in the eastern Pacific that allow even more solar radiation to reach the ocean surface. Therefore, during shorter sunspot cycles (increased solar activity), there is an increase in SSTs in the tropics and subtropics that can help explain the higher temperatures observed during regime 2. This statement can be corroborated when observing Cold Tongue Index, which usually increases during higher temperatures of positive ENSO events or positive phases of Pacific Decadal Oscillation (Mantua et al., 1997).

Pacific Decadal Oscillation (PDO) is a basin-wide phenomenon which occurs in eastern Pacific coast. It was initially described for the North Pacific, and its effects resemble to those of a weak, long-lasting ENSO event; with the positive phase similar to an El Niño and negative phase to La Niña (Trenberth, 1990; Mantua et al., 1997). In last century, two positive PDO regimes prevailed from 1890-1924 and again from 1947-1976, while warm PDO regimes dominated from 1925-1946 and from 1977 to mid-1990s (Minobe, 1997). PDO regimes and regime shifts detected seem to be in synchrony, i.e. the regime shift in PDO of late 1970's 
towards a positive phase agrees with the first regime shift detected in the present work which switched the whole basin to warm conditions. As pointed out by Gershunov and Barnett (1998), some studies suggest that ENSO influences on climate are strongly dependent on the phase of the PDO, such that the canonical El Niño and La Niña patterns of climate anomalies are most likely to occur during years in which ENSO and PDO extremes are in phase (i.e., with warm PDO coincident with El Niño, and cool PDO coincident with La Niña). During second regime (warm), the strongest ENSO events of the series were recorded, which is another resemblance between PDO and the present work. It is worth noting the synchrony of regime shifts in this work and PDO phases, which indicates a deep coupling of the climatic system in the whole basin.

The regime shift detector (RSD) was applied to the SST anomalies (Fig. 2c). What makes this method useful is the use of a statistical test which includes a measure of the level of significance. This is very useful to detect if there is any meaningful change in the mean or variance of the time series. The Hovmöller diagram of the RSD corroborates what was previously stated (Fig. 2c). There was a basin-scale SST regime shift around the year 1978 from cooler to warmer conditions. This SST regime shift occurs along the whole basin, with the exception of the region from $4^{\circ} \mathrm{S}$ to $16^{\circ}-$ $18^{\circ} \mathrm{N}$ where the regime shifts happened a little later, around mid-1980's. The warm event from $24^{\circ} \mathrm{S}$ to $60^{\circ} \mathrm{N}$ in late 1950 's is related to the occurrence of the 1957-1958 ENSO event.

The SST regime changes to cool conditions in the late 1990's. This occurred along the whole basin and it might have been triggered by la Niña 1999-2001. This event started in late 1998 and lasted through 2000 with negative anomalies observed even during 2002.

\subsection{Seasonal cycle amplitude and RSD}

The Hovmöller diagram of the temperature amplitude (TA) and temperature residual ( $\mathrm{TR}=$ range - theoretical curve of solar radiation, TC, see the methods section) are shown in Fig. 3a and $3 \mathrm{~b}$ respectively. It is important to notice that latitudinal TA is caused by seasonal changes in solar radiation; meanwhile changes in TR are likely caused by physical processes such as ocean currents capable of modifying the phase of the seasonal warming/cooling cycle due to solar irradiance.

TA in Fig. 3a clearly denotes a latitudinal gradient explained by the SST mean latitudinal range (Fig. 1a). TA was always larger than $7^{\circ} \mathrm{C}$ in the mid- to high-latitudes (from $40^{\circ} \mathrm{N}$ northwards), diminishes to a minimum of $2-4^{\circ} \mathrm{C}$ from $28^{\circ}$ to $40^{\circ} \mathrm{N}$, increasing again when it reached the tropical transition zone (from $20^{\circ}$ to $26^{\circ} \mathrm{N}$ ) and in the tropical to equatorial band the SST range was very small (less than $3{ }^{\circ} \mathrm{C}$ ). In the southern hemisphere the larger SST ranges occurred in the equatorial to subtropical band (south of $0^{\circ}$ to $26^{\circ} \mathrm{S}$ ) reaching up to $10^{\circ} \mathrm{C}$. Only the extreme south showed again a small range similar to that observed in the equator.

It is worth noting that ENSO events have a strong effect over the seasonal cycle, amplifying it or reducing it (Trenberth, 1997; Galanti and Tziperman, 1999; Neelin et al., 2000). For example in the El Niño 1997-1998 the effect differed along the coast. From the equator southwards to $30^{\circ} \mathrm{S}$ the presence of the Humboldt Current results in a reduction of the TA of 2 to $3{ }^{\circ} \mathrm{C}$. Northwards along the coast the TA was amplified in the subtropical to tropical transition $\left(20^{\circ}\right.$ to $\left.26^{\circ} \mathrm{N}\right)$ and in the mid- to high-latitude $\left(40^{\circ} \mathrm{N}\right.$ and northwards) due to the poleward propagation of the ENSO signal. After El Niño event, La Niña acted in exactly the opposite way. It amplified the SST range southwards of the equator and reduced it north of it.

When subtracting the TC from the TA (Fig. 3b) the residuals (TR) indicate how the temperature range is affected by other factors than merely solar radiation. After this calculation the results indicates that ocean currents are the physical factors most important in influencing SST.

The southernmost portion $\left(52^{\circ}-60^{\circ} \mathrm{S}\right)$ showed the lowest negative residuals $\left(-7\right.$ to $\left.-5^{\circ} \mathrm{C}\right)$ and lowest temperatures (around $5^{\circ} \mathrm{C}$ ) and is influenced by the Antarctic Circumpolar Current. This indicates that warming during austral spring and summer is greatly dispersed due to advection, turning this zone colder than the TC. Northwards, there is a zone located approximately from $50^{\circ}$ to $26^{\circ} \mathrm{S}$ influenced by the Humboldt Current (also known as Peru or Peru-Chile Current) and alongshore winds around $30^{\circ} \mathrm{S}$ (Strub et al., 1998, temperature $\sim 10-17^{\circ} \mathrm{C}$ ). The residuals here are between 0 and $-4^{\circ} \mathrm{C}$, which indicates that this zone is still cooler than expected and it has a reduced seasonal cycle. Between $24^{\circ} \mathrm{S}$ and the equator residuals are positive and reach the highest values. This region should have tropical and homogeneous temperature based on the latitude but it has a greater temperature changes during seasonal cycles than expected. This is due to the cold Humboldt Current and seasonal upwelling. From $2^{\circ}$ to $18^{\circ} \mathrm{N}$ the residuals are the smallest and slightly negative $\left(>-2{ }^{\circ} \mathrm{C}\right)$ indicating that this region has seasonal cycle smaller than the TC. This is the warmest coastal region in the eastern Pacific coast with a mean SST around $~ 27-$ $28^{\circ} \mathrm{C}$ and it is where the thermal Equator and the eastern Pacific warm pool are located. This zone is relatively stable as a consequence of the lack of a dominant large-scale circulation and high solar radiation. In the $20^{\circ}-26^{\circ} \mathrm{N}$ region, the seasonal cycle is amplified by almost $2{ }^{\circ} \mathrm{C}$ in this region where the California Current seasonally nears the coast. This region includes the transition between tropical and temperate climates but still receives a large amount of solar radiation, with the Tropic of Cancer located at $\sim 23^{\circ} 26^{\prime} 16^{\prime \prime} \mathrm{N}$. All these conditions result in a marked seasonality. From $28^{\circ}$ to $\sim 44^{\circ} \mathrm{N}$ the seasonal cycle is lower than expected $\left(-2{ }^{\circ} \mathrm{C}\right)$ basically due to the combined effect of the North $\mathrm{Pa}$ cific Current in the north, the California Current and seasonal coastal upwelling which helps in maintaining low SSTs. The 


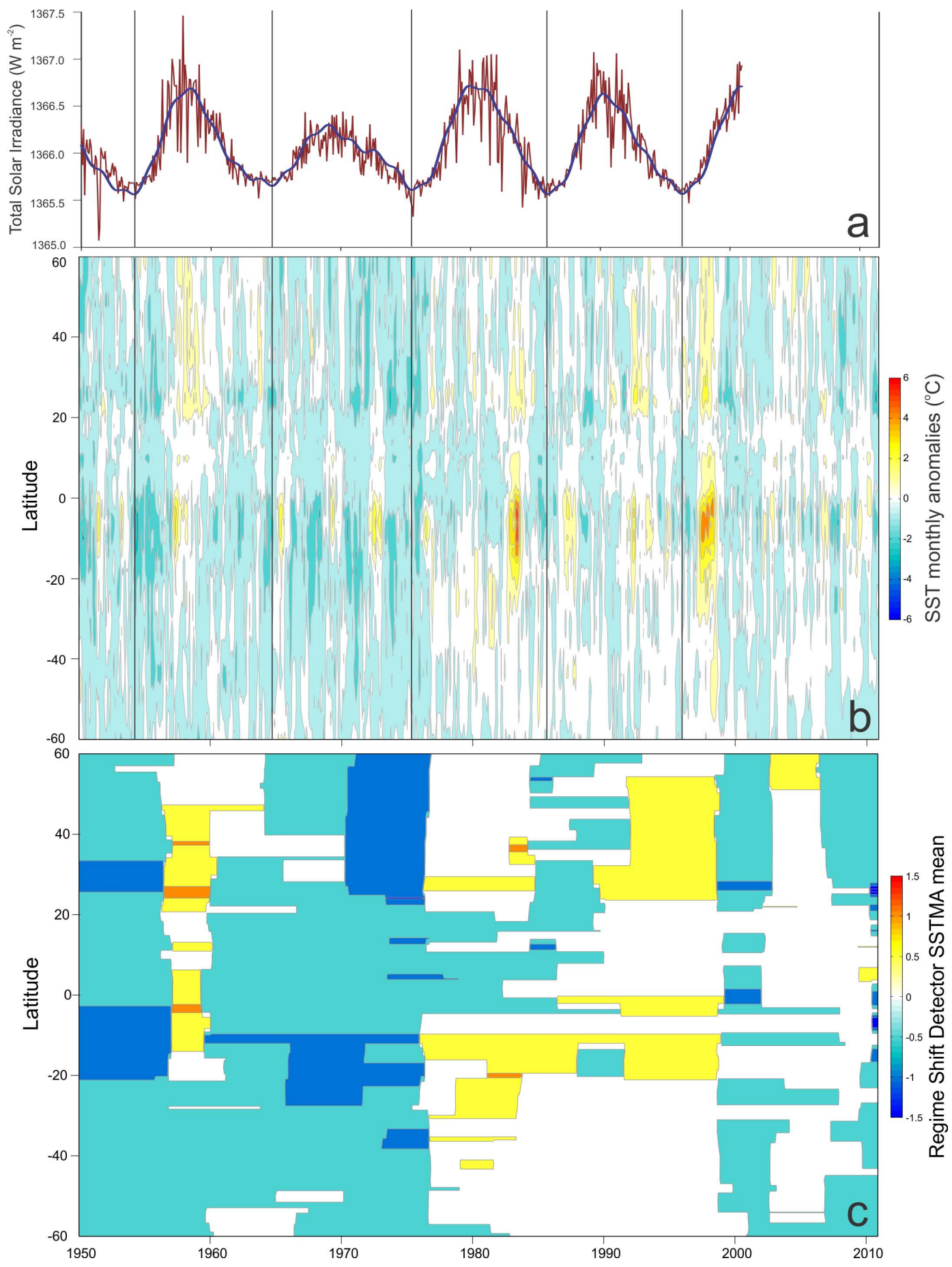

Fig. 2. Total solar radiation (a), Hovmöller diagram of the SST monthly anomalies (b) and the same type of diagram for RSD applied to SST monthly anomalies (c). The colorbar in $2 \mathrm{c}$ represents the mean value for the regime detected trough RSD in the same units as SST $\left({ }^{\circ} \mathrm{C}\right)$.

northernmost region $\left(46^{\circ}-60^{\circ} \mathrm{N}\right)$ is characterized by a seasonal cycle slightly larger than expected (up to $\sim 2{ }^{\circ} \mathrm{C}$ ), although it shows variability with negative values dominating in some periods. This is because this zone is influenced by the Alaska Current, known to be a warm current, and this interannual range variability reflects its variability near the coast. The RSD applied to TA and TR (figure not shown) showed no discernible patterns, as was the case for SST monthly anomalies. 


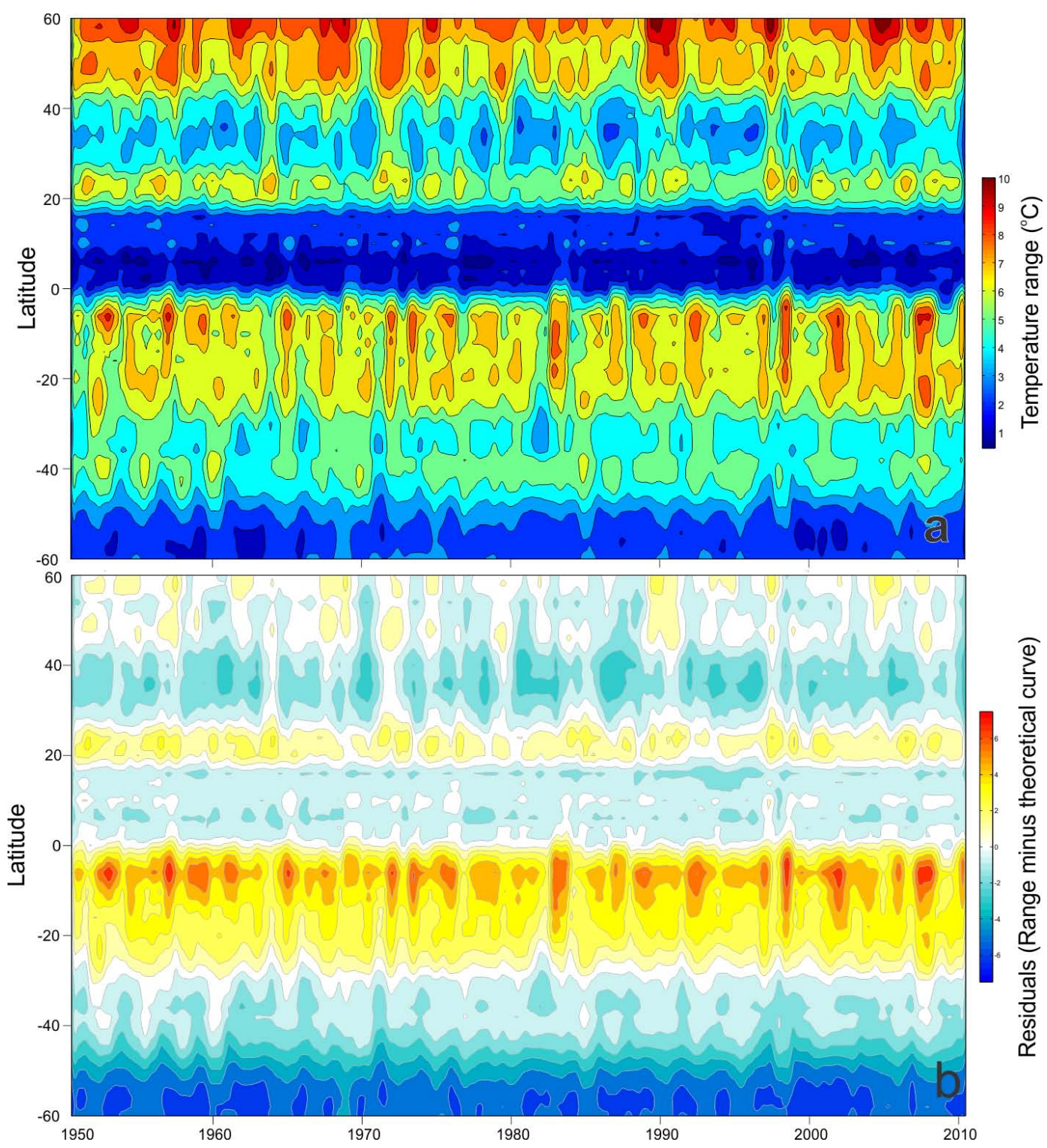

Fig. 3. Hovmöller diagram of the SST range (TA, (a)), and the residuals (TR) calculated from subtracting the theoretical curve from the range (b).

The ocean currents play an important role in the distribution of heat and momentum in the earth; in this case they alter the SST range near the coast by distributing the energy received at other latitudes. Trenberth and Caron (2001) showed different estimates of derived ocean heat transport for some oceans. They showed calculated values for the "World Ocean" at $24^{\circ}$ of $1.5-2.0 \mathrm{PW}\left(\right.$ Petawatt $\left.=10^{15} \mathrm{~W}\right)$, such values indicate the importance of the heat transport by currents.

\section{Conclusions}

In this study, during the last $61 \mathrm{yr}$ two shifts to different "temperature regimes" were detected along the coast of the eastern Pacific. This was carried out through analysis of monthly SST anomalies and using statistical tools, such as the regime shift detector (RSD). We found that the SST regimes were clearly related to the solar activity, particularly to the amount of TSI and length and intensity of sunspot cycle.

Noteworthy is the relationship observed between TSI and SST: more energy was received at the top of the atmosphere during the second SST regime -which was warmer, than in the cooler first SST regime. As stated, the difference between SST regimes is $3 \times 10^{8} \mathrm{~J} \mathrm{~m}^{-2}$. This is equivalent to about 
$0.39 \%$ more energy received during the warm SST regime compared to the cooler SST regime. Although a great percentage of the energy received at the top of the atmosphere is lost due to dispersion, refraction, reflection, etc. The remaining energy enters the climate system and the loss of about $0.39 \%$ during the cool SST regime is not a negligible amount. Another factor influencing incoming radiation from the sun in climatic regimes is the length of solar cycles that is longer during the cool SST regime ( $22 \mathrm{yr}$ combined) than the remaining two cycles in the series (21 yr combined); while the second cycle of the cool SST regime (1964-1975) received the least amount of energy of the series. Hence, it is possible that these combined factors, less energy received due to reduced solar activity because of the longer cycles and less irradiance, caused the dominance of negative anomalies in the first $\sim 30 \mathrm{yr}$ of the time series. The opposite happens in the next two cycles, more TSI and shorter sunspot cycles. The relationship between TSI and length of solar cycles is complex and not totally understood, but ideally it should not be disregarded when assessing climate affects. The seasonal cycle in the eastern coast of Ocean Pacific has not significantly changed in the 61-yr period studied. We corroborated that some climatic variability, such as ENSO events, is capable of altering the amplitude of the seasonal cycle. This has been recognized by many authors and some of them report that its effect can be superimposed on the long-term climatic alterations. Also, the seasonal cycle in coastal regions is influenced by the advection of heat by the oceanic currents. They play an important role in the modulation of the amplitude of seasonal cycles in coastal areas.

Acknowledgements. The first author wants to thank to Consejo Nacional de Ciencia y Tecnología (CONACyT) for the scholarship 48486. ATC, SELC and DBLC are SNI grant holders. We also want to thank P. Fiedler and Miguel Angel Cosío for his valuable comments about the present work.

Edited by: E. J. M. Delhez

\section{References}

Ashok, K. and Yamagata, T.: The El Niño with a difference, Nature, 461, 481-484, 2009.

Bennett, K.: Milankovitch cycles and their effects on species in ecological and evolutionary time, Paleobiology, 16, 11-21, 1990.

Bloomfield, P.: Fourier Analysis of Time Series: An Introduction, Wiley Series in Probability and Mathematical Statistics, John Wiley \& Sons, 1st edn., 1976.

Braun, H., Christl, M., Rahmstorf, S., Ganopolski, A., Mangini, A., Kubatzki, C., Roth, K., and Kromer, B.: Possible solar origin of the 1,470-year glacial climate cycle demonstrated in a coupled model, Nature, 438, 208-211, 2005.

Charvátová, I.: Can origin of the 2400-year cycle of solar activity be caused by solar inertial motion?, Ann. Geophys., 18, 399-405, doi:10.1007/s00585-000-0399-x, 2000.

Dean, W. E.: Sun and climate, USGS Fact Sheet FS-095-00, 2000.
Fiedler, P. C. and Talley, L. D.: Hydrography of the eastern tropical Pacific: A review, Prog. in Ocean., 69, 143-180, 2006.

Friis-Christensen, E. and Lassen, K.: Length of the Solar Cycle: An Indicator of Solar Activity Closely Associated with Climate, Science, 254, 698-700, 1991.

Galanti, E. and Tziperman, E.: ENSO's phase locking to the seasonal cycle in the fast-SST, fast-wave, and mixed-mode regimes, J. Atmos. Sci., 57, 2936-2950, 1999.

Gershunov, A. and Barnett, T. P.: Interdecadal Modulation of ENSO Teleconnections, Bull. Am. Meteorol. Soc., 79, 27152726, 1998.

Haigh, J. D.: The impact of solar variability on climate, Science, 272, 981-984, 1996.

Hare, S. R. and Mantua, N. J.: Empirical evidence for North Pacific regime shifts in 1977 and 1989, Prog. Oceanogr., 47, 103-145, 2000.

Isaacs, J. D.: Some ideas and frustations about fishery science, CalCoFI Reports, 18, 34-43, 1974.

Jacobs, J. M., Anderson, M. C., Friess, L. C., and Diak, G. R.: Solar radiation, longwave radiation and emergent wetland evapotranspiration estimates from satellite data in Florida, USA, Hydrolog. Sci. J., 49, 461-476, 2004.

Lean, J.: Evolution of the Sun's spectral irradiance since the maunder minimum, Geophys. Res. Lett., 27, 2425-2428, 2000.

Lean, J., Rottman, G. J., Harder, J., and Kopp, G.: Sorce contributions to new understanding of global change and solar variability, Sol. Phys., 230, 27-53, 2005.

Lean, J. L., Rottman, G. J., Kyle, H. L., Woods, T. N., Hickey, J. R., and Puga, L. C.: Detection and parameterization of variations in solar mid- and near-ultraviolet radiation (200-400 nm), J. Geophys. Res., 102, 29939-29956, 1997.

Lluch-Belda, D., Crawford, R., Kawasaki, T., MacCall, A., Parrish, R., Schwartzlose, R. A., and Smith, P. E.: World-wide fluctuations of sardine and anchovy stocks: The Regime Problem, S. Afr. J. Marine Sci., 8, 195-205, 1989.

Lluch-Belda, D., Hernandez-Vazquez, S., Lluch-Cota, D. B., Salinas-Zavala, C. A., and Schwartzlose, R. A.: The recovery of the California Sardine as related to global change, CalCoFI Reports, 33, 50-59, 1992.

Mantua, N. J., Hare, S. R., Zhang, Y., Wallace, J. M., and Francis, R. C.: A Pacific Interdecadal Climate Oscillation with Impacts on Salmon, Bull. Am. Meteorol. Soc, 78, 1069-1079, 1997.

Meehl, G. A., Washington, W. M., Wigley, T. M. L., Arblaster, J. M., and Dai, A.: Solar and greenhouse gas forcing and climate response in the twentieth century, J. Climate, 16, 426-444, 2003.

Meehl, G. A., Arblaster, J. M., Matthes, K., Sassi, F., and Loon, H. v.: Amplifying the Pacific climate system response to a small 11-year solar cycle forcing, Science, 325, 1114-1118, 2009.

Milankovitch, M.: Kanon der Erdbestrahlung und seine Andwendung auf das Eiszeiten-problem, R. Serbian Acad., Belgrade, 132, 1941.

Minobe, S.: A 50-70 Year Climatic Oscillation Over the North Pacific and North America, Geophys. Res. Lett., 24, 683-686, 1997.

Moran, J. M. and Morgan, M. D.: Meterology: The atmosphere and science of weather, Prentice-Hall, Inc., Upper Saddle River, New Jersey, 5th edition edn., 1997.

Neelin, J. D., Jin, F.-F., and Syu, H.-H.: Variations in ENSO Phase 
Locking, J. Climate, 13, 2570-2590, 2000.

Peristykh, A. N. and Damon, P. E.: Persistence of the Gleissberg 88-year solar cycle over the last 12,000 years: Evidence from cosmogenic isotopes, J. Geophys. Res., 108, SSH 1, 1-15, 2003.

Reid, G. C.: Solar total irradiance variations and the global sea surface remperature record, J. Geophys. Res., 96, 2835-2844, 1991.

Rind, D.: The Sun's role in climate variations, Science, 296, 673677, 2002.

Rodionov, S.: A sequential algorithm for testing climate regime shifts, Geophys. Res. Lett., 31, L09204, doi:10.1029/2004GL019448, 2004.

Rodionov, S.: Use of prewhitening in climate regime shift detection, Geophys. Res. Lett., 33, L12707, doi:10.1029/2006GL025904, 2006.

Rodionov, S. and Overland, J. E.: Application of a sequential regime shift detection method to the Bering Sea ecosystem, ICES J. Mar. Sci., 62, 328-332, 2005.

Sandweiss, D. H., Maasch, K. A., Chai, F., Andrus, C. F. T., and Reitzf, E. J.: Geoarchaeological evidence for multidecadal natural climatic variability and ancient Peruvian fisheries, Quaternary Res., 60, 330-334, 2004.

Scheffer, M. and Carpenter, S. R.: Catastrophic regime shifts in ecosystems: linking theory to observation, Trends Ecol. Evol., 18, 648-656, 2003.

Schwartzlose, R., Alheit, J., Bakun, A., Baumgartner, T., Cloete, R., Crawford, R., Fletcher, W., Green-Ruiz, Y., Hagen, E., Kawasaki, T., Lluch-Belda, D., Lluch-Cota, S., MacCall, A., Matsuura, Y., Nevarez-Martinez, M., Parrish, R., Roy, C., Serra, R., Shust, K., Ward, M., and Zuzunaga, J.: Worlwide large-scale fluctuations of sardine and anchovy populations, S. Afr. J. Marine Sci., 21, 289-347, 1999.

Smith, T. M. and Reynolds, R. W.: Extended reconstruction of global sea surface remperatures based on COADS data (18541997), J. Climate, 16, 1495-1510, 2003.
Smith, T. M. and Reynolds, R. W.: Improved Extended Reconstruction of SST (1854-1997), J. Climate, 17, 2466-2477, 2004.

Smith, T. M., Reynolds, R. W., Peterson, T. C., and Lawrimore, J.: Improvements to NOAA's historical merged land-ocean surface temperature analysis (1880-2006), J. Climate, 21, 2283-2296, 2008.

Spencer, J. W.: Fourier series representation of the position of the sun, Search, 2, 172, 1971.

Steele, J. H.: Regime shifts in marine ecosystems, Ecol. Appl., 8, S33-S36, 1998.

Stenseth, N. C., Mysterud, A., Ottersen, G., Hurrell, J. W., Chan, K., and Lima, M.: Ecological effects of climate fluctuations, Science, 297, 1292-1296, 2002.

Strub, P. T., Mesias, J. M., Montecino-B., V., Rutllant-C., J., and Salinas-M., S.: Coastal ocean circulation off western South America, in: The Sea Vol. 11, edited by: Robinson, A. R. and Brink, K. H., 273-313, John Wiley and Sons, 1998.

Trenberth, K. E.: Recent observed interdecadal climate changes in the Northern hemisphere, B. Am. Meteorol. Soc., 71, 988-993, 1990.

Trenberth, K. E.: The definition of El Niño, B. Am. Meteorol. Soc., 78, 2771-2777, 1997.

Trenberth, K. E. and Caron, J. M.: Estimates of Meridional Atmosphere and Ocean Heat Transports, J. Climate, 14, 3433-3443, 2001.

Vasiliev, S. S. and Dergachev, V. A.: The 2400-year cycle in atmospheric radiocarbon concentration: bispectrum of $14 \mathrm{C}$ data over the last 8000 years, Ann. Geophys., 20, 115-120, doi:10.5194/angeo-20-115-2002, 2002.

Wagner, G., Beer, J., Masarik, J., Muscheler, R., Kubik, P. W., Mende, W., Laj, C., Raisbeck, G. M., and Yiou, F.: Presence of the solar de Vries cycle (205 years) during the last ice age, J. Geophys. Res., 2, 303-306, 2001. 